\title{
Prevalence of Metabolic Syndrome and Its Association with Physical Capacity, Disability, and Self-Rated Health in Lifestyle Interventions and Independence for Elders Study Participants
}

\author{
Anda Botoseneanu, MD, PhD, ${ }^{a}{ }^{b}$ C Walter T. Ambrosius, PhD, ${ }^{d}$ Daniel P. Beavers, PhD, ${ }^{d}$ \\ Nathalie de Rekeneire, MD, ${ }^{c}$ Stephen Anton, PhD, ${ }^{e}$ Timothy Church, MD, PhD, ${ }^{f}$ \\ Sara C. Folta, PhD, ${ }^{g}$ Bret H. Goodpaster, PhD, ${ }^{b}$ Abby C. King, PhD, ${ }^{i}{ }^{i}$ Barbara J. Nicklas, PhD, ${ }^{k}$ \\ Bonnie Spring, PhD, ${ }^{l}$ Xuewen Wang, PhD, ${ }^{m}$ and Thomas M. Gill, MD, ${ }^{c}$ for the LIFE Study Groups
}

OBJECTIVES: To evaluate the prevalence of metabolic syndrome (MetS) and its association with physical capacity, disability, and self-rated health in older adults at high risk of mobility disability, including those with and without diabetes mellitus.

DESIGN: Cross-sectional analysis.

SETTING: Lifestyle Interventions and Independence for Elders (LIFE) Study.

PARTICIPANTS: Community-dwelling sedentary adults aged 70 to 89 at high risk of mobility disability (Short Physical Performance Battery (SPPB) score $\leq 9$; mean $7.4 \pm 1.6)(\mathrm{N}=1,535)$.

MEASUREMENTS: Metabolic syndrome was defined according to the 2009 multiagency harmonized criteria; outcomes were physical capacity (400-m walk time, grip strength, SPPB score), disability (composite 19-item score), and self-rated health (5-point scale ranging from excellent to poor).

From the a Department of Health Policy Studies; 'bnstitute of Gerontology, University of Michigan, Ann Arbor, Dearborn, Michigan; ${ }^{\mathrm{C}}$ Division of Geriatrics, Department of Internal Medicine, School of Medicine, Yale University, New Haven, Connecticut; ${ }^{\mathrm{d}}$ Department of Biostatistical Sciences, Wake Forest University, Winston-Salem, North Carolina; ${ }^{\mathrm{e}}$ Department of Aging and Geriatric Research, Institute on Aging, University of Florida, Gainesville, Florida; ${ }^{\mathrm{f}}$ Pennington Biomedical, Louisiana State University, Baton Rouge, Louisiana; ${ }^{\mathrm{g}}$ Friedman School of Nutrition Science and Policy, Tufts University, Boston, Massachusetts; ${ }^{\mathrm{h}}$ Metabolic Disease Program, Sanford I Burnham Medical Research Institute, Orlando, Florida; ${ }^{i}$ Department of Health Research and Policy; ${ }^{\mathrm{j}}$ Department of Medicine, Stanford Prevention Research Center, School of Medicine, Stanford University, Stanford, California; ${ }^{\mathrm{K}} \mathrm{J}$. Paul Sticht Center on Aging, School of Medicine, Wake Forest University, Winston-Salem,

North Carolina; 'Department of Preventive Medicine, Northwestern University, Chicago, Illinois; and ${ }^{\mathrm{m}}$ Department of Exercise Science,

University of South Carolina, Columbia, South Carolina.

Address correspondence to Anda Botoseneanu, Health Policy Studies, University of Michigan-Dearborn, 4901 Evergreen Road, Dearborn, MI 48128. E-mail: andabm@umich.edu

DOI: $10.1111 /$ jgs. 13205
RESULTS: The prevalence of MetS was $49.8 \%$ in the overall sample $(83.2 \%$ of those with diabetes mellitus, $38.1 \%$ of those without). MetS was associated with stronger grip strength (mean difference $(\Delta)=1.2 \mathrm{~kg}, P=.01$ ) in the overall sample and in participants without diabetes mellitus and with poorer self-rated health $(\Delta=0.1 \mathrm{~kg}$, $P<.001)$ in the overall sample only. No significant differences were found in 400-m walk time, SPPB score, or disability score between participants with and without MetS, in the overall sample or diabetes mellitus subgroups.

CONCLUSION: Metabolic dysfunction is highly prevalent in older adults at risk of mobility disability, yet consistent associations were not observed between MetS and walking speed, lower extremity function, or self-reported disability after adjusting for known and potential confounders. Longitudinal studies are needed to investigate whether MetS accelerates declines in functional status in high-risk older adults and to inform clinical and public health interventions aimed at preventing or delaying disability in this group. J Am Geriatr Soc 63:222-232, 2015.

Key words: metabolic syndrome; mobility disability; grip strength; Short Physical Performance Battery; selfrated health

$\mathbf{P}$ reserving physical capacity and reducing disability are essential for maintaining independent living in older adults. Impairments in physical capacity have been linked to subsequent disability, hospitalization, nursing home admission, and mortality, ${ }^{1-5}$ yet they represent an early enough stage in the disablement process to be responsive to restorative interventions. ${ }^{6,7}$ Consequently, better identification of treatable risk factors for age-related loss in physical capacity, especially in older adults at high risk for disability, is critical to efforts aimed at preventing disability. 
Metabolic syndrome (MetS), defined as a clustering of risk factors for cardiovascular disease and type 2 diabetes mellitus, including abdominal obesity, dyslipidemia, hypertension, and impaired glucose tolerance, is increasingly prevalent in U.S. adults aged 70 and older. ${ }^{8,9}$ Despite the ongoing controversy over the concept of MetS and questions about whether its components are additive, ${ }^{10}$ several existing studies suggest an association between MetS and poorer self-reported and objectively measured functional status in the general population of older adults. ${ }^{11-14}$ However, the link between MetS and self-reported or objectively measured functional status in older adults at high risk for disability has not been assessed. Given the high prevalence of MetS in older adults and its potential treatability, ${ }^{15}$ it is important to examine whether this clustering of risk factors may be associated with poor physical capacity and disability in individuals at high risk of disability.

In addition, numerous studies have documented the value of self-rated health (SRH), a subjective global assessment of an individual's health status, as a predictor of future disability and loss of independent living in older adults. ${ }^{16,17}$ SRH has been shown to capture a wide range of health-related phenomena, including chronic diseases, perceived functional status, and metabolic and inflammatory abnormalities, ${ }^{18-20}$ and to be a critical contributor to overall quality of life. Yet, few published studies have examined the association between MetS and SRH in the general population, ${ }^{21}$ and no study (to the knowledge of the authors of the current study) has evaluated older persons at high risk of disability; such studies are needed as a first step toward understanding whether the treatment of MetS components might improve SRH and quality of life in older adults.

The present study had two aims: to ascertain the prevalence of MetS and its components in older adults at high risk of disability in the overall sample and separately in subgroups defined according to age, sex, race, education, body mass index (BMI) category, and diabetes mellitus status and to evaluate the cross-sectional associations between MetS and physical capacity (walking speed, grip strength, lower extremity function), disability, and SRH in older adults at high risk of disability. For the second aim, it was hypothesized that participants with MetS would score worse on all outcomes (physical capacity, disability, SRH) than those without MetS. Describing the demographic distribution of MetS and its components and identifying the associations between MetS and precursors of disability in high-risk older adults may inform clinical and public health interventions aimed at maintaining functional status and reducing disability rates in older adults.

\section{METHODS}

\section{Study Design and Participants}

Baseline data from the Lifestyle Interventions and Independence for Elders (LIFE) Study, a Phase 3 multicenter randomized controlled trial of 1,635 community-dwelling sedentary older adults at high-risk of mobility disability were used. $^{22}$ The primary goal of the LIFE Study was to compare the effects of a moderate-intensity physical activ- ity (PA) program with those of a successful aging health education program on the incidence of major mobility disability (inability to walk $400 \mathrm{~m}$ ) in a vulnerable population of older adults.

Potential participants aged 70 to 89 were deemed eligible if they were sedentary $(<20 \mathrm{~min} / \mathrm{wk}$ of structured PA in the past month and $\leq 125 \mathrm{~min} / \mathrm{wk}$ of moderate PA based on 18 items from the Community Healthy Activities Model Program for Seniors (CHAMPS) PA questionnaire); ${ }^{23}$ at high risk of mobility disability based on objectively assessed lower extremity function (Short Physical Performance Battery (SPPB) score $\leq 9) ;{ }^{24}$ and able to walk $400 \mathrm{~m}$ in less than 15 minutes unassisted without sitting or leaning. The exclusion criteria were designed to identify persons who were probably incapable of fully participating in the interventions because of comorbid conditions or cognitive impairment and those for whom PA would be unsafe. The study design, protocol, and inclusion and exclusion criteria have been described in detail elsewhere. $^{22}$

For the present study, 100 participants for whom MetS status could not be ascertained because of missing data were excluded, resulting in an analytical sample of 1,535 participants.

\section{Measures}

\section{Physical Capacity, Disability, and SRH}

Three measures of physical capacity were evaluated: 400-m walk time, grip strength, and SPPB score.

Four hundred-meter walk time was the time (in seconds) that each participant needed to complete a $400-\mathrm{m}$ course walking at usual speed without sitting, leaning, or the assistance of another person or a walker. In older adults, 400-m walk time has been associated with greater risk of mobility limitation, disability, and mortality ${ }^{25}$ and serves as a proxy indicator for ability to walk within the community and thus has emerged as an important health outcome. $^{26}$

Grip strength, a commonly used measure of upper body strength with predictive value for mortality and disability, ${ }^{4,27}$ was measured in kilograms as the average of two maximal trials of the dominant hand (to the nearest $2 \mathrm{~kg}$ ) with a hand dynamometer (JAMAR; Lafayette Instrument Company, Lafayette, IN).

Short Physical Performance Battery score, ${ }^{24}$ a highly reliable and responsive summary measure of lower extremity function, ${ }^{28}$ comprises three hierarchical timed tests of balance, 4-m usual pace walking, and repeated chair stands. For each test, a five-level summary scale from 0 (unable to perform the task) to 4 (best performance) was created according to established procedure. ${ }^{24}$ An overall SPPB score (range 0-12) was calculated for each participant by summing the scores on the three tests; higher scores indicate better performance. Individuals with SPPB scores greater than 9 were excluded from the study.

Disability was assessed using the previously validated Pepper Assessment Tool for Disability questionnaire. ${ }^{29}$ The items covered three domains: basic activities of daily living (ADLs: getting in and out of a chair, getting in and 
out of a bed, gripping with hands, using the toilet, dressing, getting in and out of a car, walking across a small room, bathing), mobility (walking several blocks, lifting heavy objects, walking one block, lifting or carrying 10 pounds, climbing several flights of stairs, climbing one flight of stairs, walking one-quarter of a mile), and instrumental activities of daily living (IADLs: light housework, participating in community activities, managing money, visiting with relatives or friends, using the telephone, taking care of a family member). Respondents were asked to report the level of difficulty they had with each item during the past month; responses were coded on a 5-point Likert scale, ranging from 1 (usually no difficulty) to 5 (unable to do), and scores were averaged to generate a summary score, with higher mean scores denoting greater disability.

Self-rated health was measured using participants ratings of their general health status, ${ }^{30}$ as indicated by their response to the question: "Would you say your general health is...?"; ratings ranged from 1 (excellent) to 5 (poor).

\section{Metabolic Syndrome (MetS)}

MetS was defined in accordance with the harmonized criteria recommended in the 2009 Joint Interim Statement from multiple scientific associations ${ }^{31}$ as the presence of three or more components from the following: abdominal obesity (waist circumference $\geq 102 \mathrm{~cm}$ in men and $\geq 88 \mathrm{~cm}$ in women measured at the midpoint between the highest point of the iliac crest and the lowest part of the costal margin in the midaxillary line), low high-density lipoprotein cholesterol HDL-C $(<40 \mathrm{mg} / \mathrm{dL}$ for men and $<50 \mathrm{mg} /$ $\mathrm{dL}$ for women or drug treatment for low HDL-C), high triglycerides (TG) $(\geq 150 \mathrm{mg} / \mathrm{dL}$ or drug treatment for high TG), hypertension (systolic blood pressure $\geq 130 \mathrm{mmHg}$, diastolic pressure $\geq 85 \mathrm{mmHg}$, or antihypertensive drug treatment with a history of physician-diagnosed high blood pressure), and high fasting plasma glucose $(\geq 100 \mathrm{mg} / \mathrm{dL}$ or drug treatment for diabetes mellitus). MetS was coded as a binary variable (absent vs present).

Blood samples were collected after a 12-hour fast. All samples were tested in a single laboratory; before testing, all samples were stored and transferred according to protocol. Participants were asked to bring all current medications with them, and medications were reviewed at the phlebotomy visit.

\section{Covariates}

\section{Comorbidities}

Self-reported, physician-diagnosed diabetes mellitus (absent vs present) was recorded for stratified analyses. A comorbidity index (range 0-5) for other conditions was created by summing participant reports of physician-diagnosed angina pectoris or myocardial infarction, congestive heart failure, stroke, and cancer (no or yes for all four conditions) and peripheral arterial disease as determined through measurement of ankle-brachial index (ABI). Peripheral arterial disease was coded as absent if ABI was 0.9 or greater and present if ABI was less than 0.9. ${ }^{32}$
Cognitive status was assessed using the Modified Mini-Mental State (3MS) examination, ${ }^{33}$ with scores ranging from 0 to 100 ; higher scores indicate better cognitive function.

\section{Health Risk Factors}

Body mass index was calculated from measured weight and height (weight $(\mathrm{kg}) /$ height $\left.^{2}(\mathrm{~m})\right)$. PA level was assessed according to CHAMPS score (range 0-120). ${ }^{23}$ Smoking status (nonsmoker vs current smoker) and alcohol use (nondrinker, $<1 \mathrm{drink} / \mathrm{d}, \geq 1 \mathrm{drink} / \mathrm{d}$ ) were also recorded at baseline.

\section{Statistical Analysis}

Descriptive statistics were calculated for all variables. Cochran-Armitage trend tests and chi-square tests were used to compare proportions of MetS (and each component of MetS) in baseline subgroups. Linear models were used to compare participants with and without MetS in unadjusted and adjusted models. The following covariates were used in the adjusted models: demographic (sex, race, education, age, field site), health status (comorbidity index, 3MSE), health risk factors (BMI category, CHAMPS score, smoking status, alcohol use), and diabetes mellitus (only for the overall sample models). Differences of adjusted means and confidence intervals were also calculated. These analyses were completed for the overall sample and for subgroups defined on the basis of diabetes mellitus status. No explicit adjustment was made for multiple comparisons.

Because of earlier reports showing associations between severity of MetS or individual MetS components and several of the outcomes investigated here, ${ }^{34-37}$ additional analyses were performed using MetS as an ordinal variable (to capture the severity of metabolic dysfunction as indicated by the number of MetS components identified in each participant) and separately with each MetS component. All secondary analyses were adjusted for the covariates described for the main analyses.

\section{RESULTS}

Participants' demographic and health characteristics are described in Table 1 for the full sample and separately for participants with and without MetS; $764(49.8 \%)$ participants had three or more MetS components, fulfilling the requirements for MetS (MetS subgroup), and 771 (50.2\%) had two or fewer components (non-MetS subgroup). The MetS and non-MetS subgroups were generally comparable on all characteristics except diabetes mellitus and obesity, both of which were substantially more common in the MetS subgroup.

Hypertension was the most common component in the MetS $(93.2 \%)$ and non-MetS $(63.8 \%)$ subgroups, followed by abdominal obesity $(92.7 \%$ and $52.8 \%)$; low HDL-C was the least common component in both subgroups $(42.8 \%$ and $2.2 \%)$. The majority $(54.3 \%)$ of MetS participants met three metabolic criteria, and $54.1 \%$ of non-MetS participants met two metabolic criteria. 
Table 1. Characteristics of Study Participants According to Metabolic Syndrome (MetS)

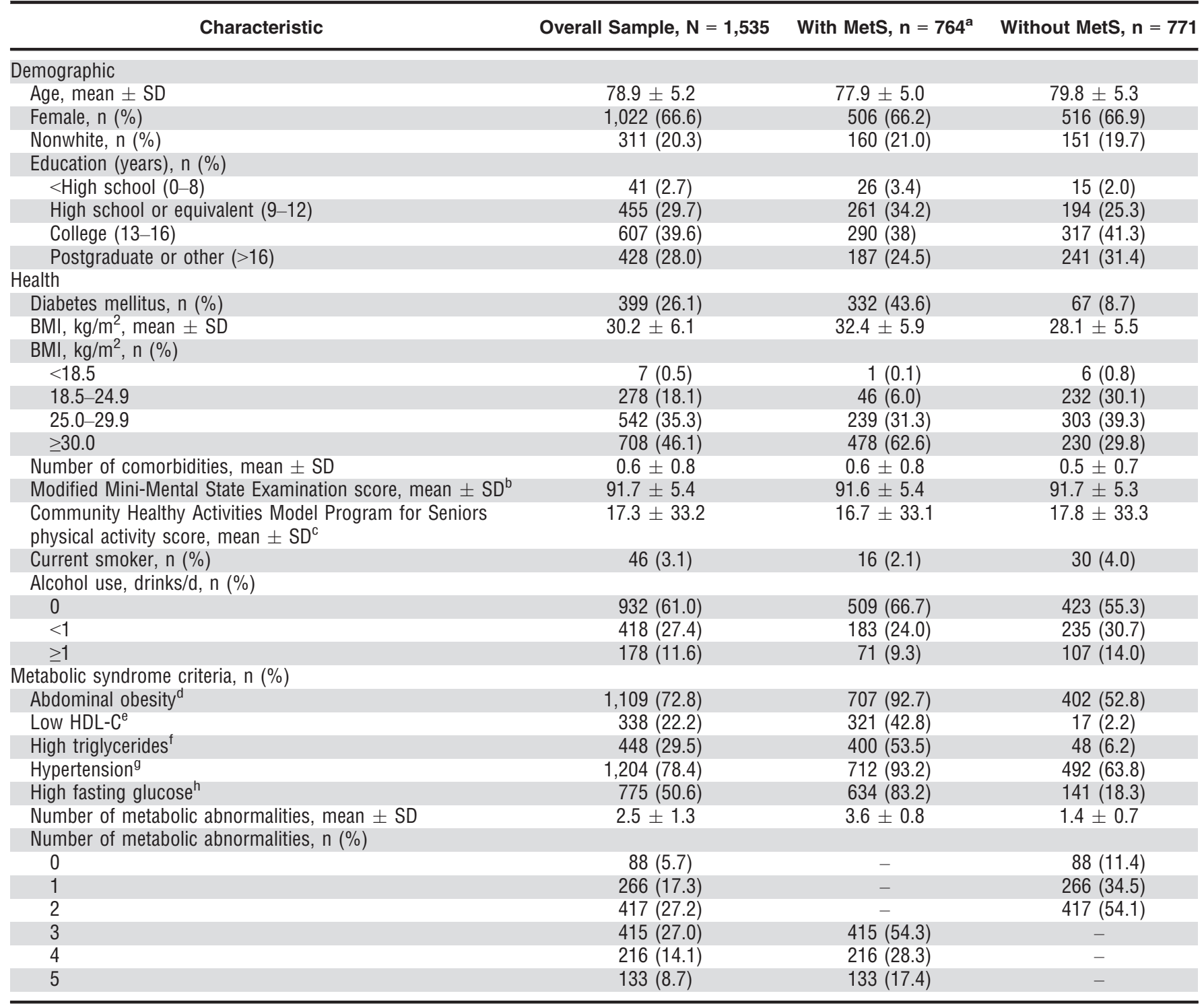

Missing values account for the small discrepancies between total $\mathrm{n}$ (in each column) and the values listed under each descriptive characteristic.

${ }^{a} \geq 3$ criteria.

${ }^{\mathrm{b}}$ Range 0-100; higher score indicates better cognitive function.

${ }^{\mathrm{c}}$ Range 0-120; higher score indicates higher levels of physical activity.

${ }^{\mathrm{d}}$ Waist circumference $\geq 102 \mathrm{~cm}$ in men, $\geq 88 \mathrm{~cm}$ in women.

e $<40 \mathrm{mg} / \mathrm{dL}$ for men, $<50 \mathrm{mg} / \mathrm{dL}$ for women or drug treatment for low high-density lipoprotein cholesterol (HDL-C).

${ }^{\mathrm{f}} \geq 150 \mathrm{mg} / \mathrm{dL}$ or drug treatment for high triglycerides.

g Systolic blood pressure $\geq 130 \mathrm{mmHg}$, diastolic blood pressure $\geq 85 \mathrm{mmHg}$, or antihypertensive drug treatment with a history of physician-diagnosed hypertension.

$\mathrm{h} \geq 100 \mathrm{mg} / \mathrm{dL}$ or drug treatment for diabetes mellitus.

$\mathrm{SD}=$ standard deviation; $\mathrm{BMI}=$ body mass index.

\section{Prevalence of MetS and Individual Components}

Table 2 presents the prevalence of MetS and individual MetS components according to selected participant characteristics.

\section{MetS Prevalence}

The prevalence of MetS was similar in men and women and in whites and nonwhites. Older age and greater education were associated with progressively lower rates of
MetS. As expected, the prevalence of MetS was greater with higher BMI category and was substantially higher in participants with diabetes mellitus than in those without.

\section{Individual MetS Components}

Fasting glucose was the only metabolic risk factor that differed between men and women (more prevalent in men). Racial differences were identified only in the prevalence of high TG (higher in whites) and hypertension (higher in nonwhites). Older age was associated with lower rates of 
Table 2. Prevalence of Metabolic Syndrome (MetS) and Individual Components According to Selected Sample Characteristics $(\mathrm{N}=1,535)$

\begin{tabular}{|c|c|c|c|c|c|c|}
\hline Characteristic & $\begin{array}{l}\text { Mets } \\
(\geq 3 \text { Criteria) }\end{array}$ & $\begin{array}{l}\text { Abdominal } \\
\text { Obesity }^{\mathrm{a}}\end{array}$ & $\begin{array}{l}\text { Low } \\
\text { HDL-C }\end{array}$ & $\begin{array}{l}\text { High } \\
\text { Triglycerides }^{c}\end{array}$ & Hypertension $^{d}$ & $\begin{array}{l}\text { High Fasting } \\
\text { Glucose }^{\mathrm{e}}\end{array}$ \\
\hline \multicolumn{7}{|l|}{ Age } \\
\hline $70-74$ & 59.2 & 85.6 & 25.7 & 33.5 & 77.9 & 56.2 \\
\hline $75-79$ & 54.1 & 75.5 & 23.7 & 30.5 & 79.9 & 53.6 \\
\hline $80-84$ & 45.2 & 67.2 & 21.8 & 29.9 & 78.4 & 48.0 \\
\hline $85-89$ & 32.4 & 53.8 & 13.9 & 19.7 & 76.9 & 39.2 \\
\hline$P$-value & $<.001$ & $<.001$ & .001 & .001 & .76 & $<.001$ \\
\hline \multicolumn{7}{|l|}{ Sex } \\
\hline Female & 49.5 & 74.3 & 22.1 & 29.5 & 79.1 & 47.3 \\
\hline Male & 50.3 & 69.8 & 22.5 & 29.5 & 77.2 & 57.2 \\
\hline$P$-value & .77 & .07 & .87 & .97 & .40 & $<.001$ \\
\hline \multicolumn{7}{|l|}{ Race } \\
\hline Nonwhite & 51.4 & 77.0 & 18.3 & 19.4 & 86.5 & 53.7 \\
\hline White & 49.4 & 71.7 & 23.3 & 32.1 & 76.3 & 49.8 \\
\hline$P$-value & .52 & .06 & .06 & $<.001$ & $<.001$ & .22 \\
\hline \multicolumn{7}{|l|}{ Education (years) } \\
\hline$<$ High school $(0-8)$ & 63.4 & 78.0 & 41.5 & 43.9 & 80.5 & 61.0 \\
\hline High school or equivalent (9-12) & 57.4 & 76.9 & 24.3 & 30.9 & 84.6 & 53.7 \\
\hline College (13-16) & 47.8 & 70.9 & 21.1 & 30.2 & 76.6 & 48.6 \\
\hline Postgraduate or other $(>16)$ & 43.7 & 70.5 & 20.0 & 25.9 & 74.5 & 49.5 \\
\hline$P$-value & $<.001$ & .02 & .01 & .02 & $<.001$ & .09 \\
\hline \multicolumn{7}{|l|}{ Body mass index, $\mathrm{kg} / \mathrm{m}^{2}$} \\
\hline$<18.5$ & 14.3 & 0.0 & 14.3 & 14.3 & 85.7 & 28.6 \\
\hline $18.5-24.9$ & 16.5 & 14.5 & 13.7 & 17.4 & 64.4 & 29.2 \\
\hline $25.0-29.9$ & 44.1 & 69.3 & 20.4 & 27.8 & 78.4 & 47.6 \\
\hline$\geq 30.0$ & 67.5 & 98.7 & 27.1 & 35.7 & 83.9 & 61.4 \\
\hline$P$-value & $<.001$ & $<.001$ & $<.001$ & $<.001$ & $<.001$ & $<.001$ \\
\hline \multicolumn{7}{|l|}{ Diabetes mellitus diagnosis } \\
\hline No & 38.1 & 68.8 & 18.2 & 26.4 & 76.2 & 35.2 \\
\hline Yes & 83.2 & 84.1 & 34.1 & 38.8 & 85.0 & 94.5 \\
\hline$P$-value & $<.001$ & $<.001$ & $<.001$ & $<.001$ & $<.001$ & $<.001$ \\
\hline
\end{tabular}

Chi-square tests were used when comparing two subgroups and the Cochran-Armitage trend tests for more than two subgroups.

a Waist circumference $\geq 102 \mathrm{~cm}$ in men, $\geq 88 \mathrm{~cm}$ in women.

b $<40 \mathrm{mg} / \mathrm{dL}$ for men, $<50 \mathrm{mg} / \mathrm{dL}$ for women or drug treatment for low high-density lipoprotein cholesterol (HDL-C).

c $\geq 150 \mathrm{mg} / \mathrm{dL}$ or drug treatment for high triglycerides.

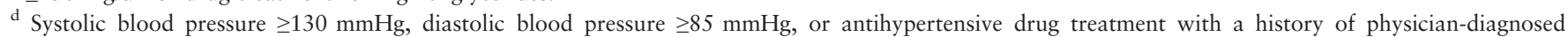
hypertension.

e $\geq 100 \mathrm{mg} / \mathrm{dL}$ or drug treatment for diabetes mellitus.

Table 3. Physical Capacity, Disability Score, and Self-Rated Health According to Metabolic Syndrome (MetS)

Overall Sample, $\mathrm{N}=\mathbf{1 , 5 3 5}$

With MetS, $\mathrm{n}=764 \quad$ Without MetS, $\mathrm{n}=771 \quad P$-Value ${ }^{\mathrm{a}}$ Mean \pm Standard Deviation

\begin{tabular}{lccc}
\hline Physical Capacity & & & \\
400-m walk time, seconds & $508.5 \pm 113.7$ & $518.4 \pm 115.8$ & $498.7 \pm 110.8$ \\
Grip strength, kg & $23.6 \pm 9.4$ & $24.4 \pm 9.9$ & .001 \\
Short Physical Performance Battery score $^{\mathrm{b}}$ & $7.38 \pm 1.59$ & $7.35 \pm 1.60$ & .002 \\
Disability score $^{\mathrm{c}}$ & $1.40 \pm 0.39$ & $1.43 \pm 0.40$ & $7.40 \pm 1.58$ \\
Self-rated health $^{\mathrm{d}}$ & $2.76 \pm 0.77$ & $2.87 \pm 0.74$ & .48 \\
\hline
\end{tabular}

${ }^{a} P$-values for unadjusted differences in physical capacity measures, disability score, and self-rated health between participants with and without MetS.

${ }^{\mathrm{b}}$ Range 1 (low) to 9 (high).

${ }^{\mathrm{c}}$ Range 1 (no difficulty reported) to 5 (unable to do tasks).

${ }^{\mathrm{d}}$ Range 1 (excellent) to 5 (poor).

all metabolic abnormalities except hypertension, and higher education was associated with lower rates of all criteria except high fasting glucose. The prevalence of each metabolic component was greater with higher BMI and was higher in participants with diabetes mellitus than in those without.
Associations Between MetS and Physical Capacity, Disability, and SRH

The results from unadjusted analyses (shown in Table 3 for the full sample and separately according to MetS status) indicate that participants with MetS walked more 
slowly on the 400-m walk test and had higher disability scores and worse SRH than those without MetS. Grip strength was significantly higher in participants with MetS than in those without. SPPB scores were similar in the two subgroups.

The mean estimated differences in all outcome scores from the unadjusted and adjusted models are presented in Table 4.

In the overall sample, MetS was associated with stronger grip strength, although the mean difference was diminished in the adjusted model $(1.2 \mathrm{~kg}, P=.01$ adjusted vs $1.6 \mathrm{~kg}, P=.001$ unadjusted). After adjustment for all covariates (listed in the footnote to Table 4), the associations between MetS and 400-m walking speed and between MetS and disability score were not statistically significant. MetS was not associated with SPPB scores in the unadjusted or adjusted models, although in both sets of models, SRH scores were significantly worse (higher) in individuals with MetS.

In participants with diabetes mellitus, there was no significant association between MetS and any of the physical capacity measures in unadjusted or adjusted analyses. The differences in disability and SRH scores observed between individuals with MetS and diabetes mellitus and those with diabetes mellitus without MetS were not statistically significant after adjustment for the demographic and health covariates. In participants without diabetes mellitus, MetS was associated with stronger grip strength in unadjusted and adjusted models, but no association was observed between MetS and the remaining four outcomes in the adjusted models.

Secondary analyses (data available upon request) with MetS as an ordinal variable showed that SRH worsened progressively as the number of MetS components increased ( $b=0.04, P=.01)$, but the severity of MetS was not significantly associated with any of the other outcomes. Finally, separate analyses with each MetS component yielded only nonsignificant results for walking speed, grip strength, SPPB, and disability score. In the overall sample, all components with the exception of abdominal obesity $(P=.86)$ were associated with worse SRH $(P=.02$ for TG, $P=.02$ for HDL, $P=.01$ for BP, $P<.001$ for glucose); in analyses stratified according to diabetes mellitus status, the only association that remained statistically significant was between low HDL-C and worse SRH in participants without diabetes mellitus $(P=.04)$.

\section{DISCUSSION}

This study offers three main findings. First, MetS was highly prevalent in this sample of adults aged 70 and older at high risk of disability, being identified in one out of two participants. Second, the prevalence of MetS and its components differed according to participants' age, education, BMI, and diabetes mellitus status. Third, after adjustment for known and potential confounders, MetS was associated with stronger grip strength (in the overall sample and in participants without diabetes mellitus) and worse SRH (in the overall sample only) but not with walking speed, SPPB score, or self-reported disability.

Understanding the current demographic distribution of MetS and its components in older adults at risk of disability 
may help to customize clinical and public health initiatives aimed at reducing disability in older adults. In contrast to previous findings showing a higher prevalence of MetS and abdominal obesity in women than in men ${ }^{8,38-40}$ the current study found only a higher rate of glucose intolerance in men. The cardiometabolic profiles of men and women were otherwise comparable. Higher educational achievement was correlated with lower rates of MetS and all its components except high blood glucose. An age-related decrease in the prevalence of MetS after age 70 was also found, from approximately $60 \%$ of participants younger than 75 to approximately $30 \%$ in the oldest group $(\geq 85)$, with a decreasing prevalence of all MetS components with advancing age except for hypertension. The cross-sectional nature of the data precluded further investigation of whether the observed association between older age and "better" metabolic profiles is due to true age differences (improvement in levels of metabolic markers with age), to differences between older and younger cohorts (worse metabolic profiles in younger cohorts), or to a healthy-survivor effect ("resilient" individuals with better metabolic profiles surviving longer than those with worse metabolic profiles). Although these findings on educational and age differences in the rates of MetS and its components are generally consistent with nationally representative estimates from the National Health and Nutrition Examination Survey using the new harmonized MetS definition ${ }^{8}$ and with other studies that have investigated sociodemographic determinants of metabolic dysfunction, ${ }^{41,42}$ more research, particularly using longitudinal data, is needed to better understand the mechanisms underlying such differences.

Previous investigations of the relationship between MetS and various objective indicators of physical capacity have focused on the general population of older adults, rather than on those at high risk of disability, with mixed results; although several studies have found weaker grip strength, slower walking speed, and poorer balance in participants with MetS than in those without, ${ }^{12-14}$ others have found no such associations. ${ }^{35}$ The results from the current sample of high-risk older adults show that the association with MetS varies across the three measures of physical capacity. First, walking speed was comparable in participants with and without MetS in the adjusted model and separately in participants with and without diabetes mellitus, indicating that the difference in walking speed observed in the unadjusted model was due to other demographic and health differences between the MetS subgroups. Furthermore, there were no associations between walking speed and individual MetS components or severity of MetS. The relationship between metabolic profiles and walking speed has been evaluated in women ${ }^{43}$ or men only ${ }^{12}$ or in general-risk populations. ${ }^{35}$ Because these studies have reported conflicting results, further research is needed to substantiate the current study's findings.

Second, in contradiction to the hypothesis and to results from several previous studies, ${ }^{14,44}$ grip strength was stronger in the overall MetS subgroup and in participants with MetS and without diabetes mellitus. Although this seemingly paradoxical finding cannot be fully explained, it is possible that the higher BMI in MetS participants than in those without was a reflection of not only higher fat mass (as indicated by the higher rates of abdominal obesity in the MetS group), but also of higher muscle mass than in the non-MetS group, resulting in better grip strength. Although body composition measures were not available for further analysis, a prior study showing that, for all BMI categories, older persons with MetS had higher muscle mass than those with a similar BMI but no MetS indirectly supports this explanation. ${ }^{39}$ Additional studies are warranted to confirm the finding and to investigate potential mechanisms linking MetS to upper extremity muscle mass and grip strength.

Third, lower extremity function as measured according to SPPB score was not associated with MetS in any of the models or subgroups. Although these results may reflect a true lack of association between lower extremity function and MetS, they may also represent a statistical artifact. Based on the eligibility criteria, LIFE participants were required to be able to walk unassisted at a speed compatible with independent living (excluding those at the very low end of SPPB scores) and to be at high risk of mobility disability as indicated by an SPPB score of 9 or less. By reducing variability across subgroups, the truncated range of SPPB scores in the resulting sample may have limited the ability to detect differences.

After adjustment for demographic and health characteristics, no differences were found in disability scores, which combined self-reports of mobility abilities and ADLs and IADLs, according to MetS status in the full sample or in the subgroups with and without diabetes mellitus. The existing literature is also conflicting regarding the relationship between MetS and self-reported functional status in the general older population; although some studies have shown a greater burden of mobility and IADL disability in the setting of MetS, ${ }^{34,45}$ others have found no association $^{46}$ and even a protective effect of MetS on ADL disability. ${ }^{44}$ Because of differences in the initial risk profile (high disability risk vs general population) and disability assessment between the current study sample and samples from prior studies, the results of the current study cannot lend support to either side. Additional research is needed to further evaluate the cross-sectional and longitudinal associations between potentially treatable metabolic abnormalities and various domains of disability in older adults.

In the overall sample, participants with MetS had marginally worse self-assessments of health than their nonMetS counterparts. Self-rated health also showed a gradient according to MetS severity and was independently associated with several MetS components in the overall sample and with low HDL-C in participants without diabetes mellitus, but the clinical significance of these differences (the largest difference between MetS and non-MetS participants was 0.2 in the overall sample) is uncertain because the minimum or meaningful clinically important difference ${ }^{47}$ in SRH has not been clearly established.

The value of MetS, in addition to that of its individual components, as an independent predictor of other important health outcomes has been called into question. ${ }^{10}$ The current study found nonsignificant associations between the MetS composite and walking speed, lower extremity function, and self-reported disability, and between individual MetS components and MetS severity and most outcomes (except SRH). Although these results may reflect a true lack of association, two alternate explanations need 
to be considered. First, it is possible that the LIFE recruitment strategy, which excluded individuals at the high and low end of functional status, may have restricted the range of variation in these outcomes and thus reduced the power to detect statistically significant differences. Second, the nonsignificant effect of MetS on these and other outcomes may be due to selective survival; specifically, members of the cohort who were "susceptible" to the negative influence of MetS may have already died, resulting in a study population comprised of "MetS resistant" individuals. The cross-sectional nature of the data prevented further investigation into the possibility of selection or survival bias. Longitudinal analyses are warranted to determine whether MetS is associated with reductions in physical capacity and greater disability in later life. A third limitation of this study is the use of a summary disability score; although the disability assessment instrument has been shown to be valid, reliable, and sensitive to change, ${ }^{29}$ it may have obscured more subtle associations between MetS and selected functional domains (mobility, ADLs, IADLs) or tasks. Fourth, because the participants were enrolled in the LIFE Study, a randomized controlled trial aimed at preventing mobility decline in older, sedentary men and women with an SPPB score of 9 or less, the results may not be generalizable to individuals who do not meet these criteria. Nonetheless, given that many older adults in the United States are sedentary and have functional limitations, the results are likely to be representative of a substantial proportion of community-living older men and women.

Although approximately half of older adults at risk of mobility disability participating in the LIFE Study have metabolic profiles consistent with MetS, an association between MetS and walking speed, lower extremity function, and self-reported disability remains to be established. Longitudinal studies are needed to investigate whether the metabolic dysregulation characterized by MetS accelerates declines in functional status over time. This knowledge may in turn inform clinical and public health interventions aimed at preventing or delaying disability in older adults.

\section{ACKNOWLEDGMENTS}

The LIFE Study is funded by National Institutes of Health (NIH), National Institute on Aging (NIA) Cooperative Agreement U01AG22376 and a supplement from the National Heart, Lung, and Blood Institute (3U01AG022376). It is sponsored in part by the Intramural Research Program, NIA, NIH. Complete acknowledgments and funding information are shown in Appendix 1 and are available at https://www.thelifestudy.org/docs/ LIFE-AcknowledgementList11_2014-02-17_Full\%20List_clean.pdf.

Conflict of Interest: The editor in chief has reviewed the conflict of interest checklist provided by the authors and has determined that the authors have no financial or any other kind of personal conflicts with this paper.

Dr. Botoseneanu was funded by NIA Grant T32AG19134. Dr. Anton is supported by NIH Grant K23AT004251, the Florida Claude D. Pepper Older Americans Independence Center (P30AG028740), and the
Thomas H. Maren Foundation. Dr. Spring was funded by Grants HL075451 from the National Heart, Lung, and Blood Institute and DK087126 from the National Institute of Diabetes, Digestive, and Kidney Disease. Dr. Gill is the recipient of an Academic Leadership Award (K07AG043587) from the NIA and is supported by the Yale Claude D. Pepper Older Americans Independence Center (P30AG21342).

Author Contributions: Botoseneanu, Gill: concept and design. Ambrosius, Beavers: statistical analyses. Botoseneanu, Gill, Ambrosius: interpretation of results. Botoseneanu, Ambrosius, Gill: drafting the manuscript. Gill, de Rekeneire, Anton, Church, Folta, Goodpaster, King, Spring: acquisition of data. Botoseneanu, Gill, Ambrosius, Beavers, de Rekeneire, Anton, Church, Folta, Goodpaster, King, Nicklas, Spring, Wang: critical revision and finalizing of manuscript. All authors approved the advanced version for publication.

Sponsor's Role: None.

\section{REFERENCES}

1. Studenski S, Perera S, Patel K et al. Gait speed and survival in older adults. JAMA 2011;305:50-58.

2. Rantanen T, Volpato S, Ferrucci L et al. Handgrip strength and cause-specific and total mortality in older disabled women: Exploring the mechanism. J Am Geriatr Soc 2003;51:636-641.

3. Penninx BWJH, Ferrucci L, Leveille SG et al. Lower extremity performance in nondisabled older persons as a predictor of subsequent hospitalization. J Gerontol A Biol Sci Med Sci 2000;55A:M691-M697.

4. Rantanen T, Guralnik JM, Foley D et al. Midlife hand grip strength as a predictor of old age disability. JAMA 1999;281:558-560.

5. Guralnik JM, Ferrucci L, Pieper CF et al. Lower extremity function and subsequent disability. J Gerontol A Biol Sci Med Sci 2000;55A:M221M231.

6. Seeman TE, Berkman LF, Charpentier PA et al. Behavioral and psychosocial predictors of physical performance: MacArthur Studies of Successful Aging. J Gerontol A Biol Sci Med Sci 1995;50A:M177-M183.

7. Pahor M, Blair SN, Espeland M et al. Effects of a physical activity intervention on measures of physical performance: Results of the Lifestyle Interventions and Independence for Elders Pilot (LIFE-P) study. J Gerontol A Biol Sci Med Sci 2006;61A:1157-1165.

8. Ford ES, Li C, Zhao G. Prevalence and correlates of metabolic syndrome based on a harmonious definition among adults in the US. J Diabetes 2010;2:180-193.

9. Mozumdar A, Liguori G. Persistent increase of prevalence of metabolic syndrome among US adults: NHANES III to NHANES 1999-2006. Diabetes Care 2011;34:216-219.

10. Samaras K, Crawford J, Baune BT et al. The value of the metabolic syndrome concept in elderly adults: Is it worth less than the sum of its parts? J Am Geriatr Soc 2012;60:1734-1741.

11. Blazer DG, Hybels CF, Fillenbaum GG. Metabolic syndrome predicts mobility decline in a community-based sample of older adults. J Am Geriatr Soc 2006;54:502-506.

12. Everson-Rose SA, Paudel M, Taylor BC et al. Metabolic syndrome and physical performance in elderly men: The Osteoporotic Fractures in Men Study. J Am Geriatr Soc 2011;59:1376-1384.

13. Beavers KM, Hsu F, Houston DK et al. The role of metabolic syndrome, adiposity, and inflammation in physical performance in the HealthABC study. J Gerontol A Biol Sci Med Sci 2013;68A:617-623.

14. Sayer AA, Syddall HE, Dennison EM et al. Grip strength and the metabolic syndrome: Findings from the Hertfordshire Cohort Study. QJM 2007;100:707-713.

15. Akbaraly TN, Singh-Manoux A, Tabak AG et al. Overall diet history and reversibility of the metabolic syndrome over 5 years the Whitehall II Prospective Cohort Study. Diabetes Care 2010;33:2339-2341.

16. Idler EL, Kasl SV. Self-ratings of health: Do they also predict change in functional ability? J Gerontol B Psychol Sci Soc Sci 1995;50B:S344.

17. Idler EL, Russell LB, Davis D. Survival, functional limitations, and selfrated health in the NHANES I Epidemiologic Follow-Up Study, 1992. Am J Epidemiol 2000;152:874-883. 
18. Okosun IS, Choi S, Matamoros $\mathrm{T}$ et al. Obesity is associated with reduced self-rated general health status: Evidence from a representative sample of white, black, and Hispanic Americans. Prev Med 2001;32: 429-436.

19. Jylhä M, Guralnik JM, Balfour J et al. Walking difficulty, walking speed, and age as predictors of self-rated health: The Women's Health and Aging Study. J Gerontol A Biol Sci Med Sci 2001;56A:M609-M617.

20. Leinonen R, Heikkinen E, Jylhä M. Predictors of decline in self-assessments of health among older people - a 5-year longitudinal study. Soc Sci Med 2001;52:1329-1341.

21. Näslindh-Ylispangar A, Sihvonen M, Vanhanen H et al. Self-rated health and risk factors for metabolic syndrome among middle-aged men. Public Health Nurs 2005;22:515-522.

22. Fielding RA, Rejeski WJ, Blair S et al. The Lifestyle Interventions and Independence for Elders Study: Design and methods. J Gerontol A Biol Sci Med Sci 2011;66A:1226-1237.

23. Stewart AL, Mills KM, King AC et al. CHAMPS physical activity questionnaire for older adults: Outcomes for interventions. Med Sci Sports Exerc 2001;33:1126-1141.

24. Guralnik JM, Simonsick EM, Ferrucci L et al. A short physical performance battery assessing lower extremity function: Association with selfreported disability and prediction of mortality and nursing home admission. J Gerontol A Biol Sci Med Sci 1994;49A:M85-M94.

25. Newman AB, Simonsick EM, Naydeck BL et al. Association of long-distance corridor walk performance with mortality, cardiovascular disease, mobility limitation, and disability. JAMA 2006;295:2018-2026.

26. Shumway-Cook A, Guralnik JM, Phillips CL et al. Age-associated declines in complex walking task performance: The Walking InCHIANTI toolkit. J Am Geriatr Soc 2007;55:58-65.

27. Rantanen T, Harris TB, Leveille SG et al. Muscle strength and body mass index as long-term predictors of mortality in initially healthy men. J Gerontol A Biol Sci Med Sci 2000;55A:M168-M173.

28. Ostir GV, Volpato S, Fried LP et al. Reliability and sensitivity to change assessed for a summary measure of lower body function: Results from the Women's Health and Aging Study. J Clin Epidemiol 2002;55:916921.

29. Rejeski WJ, Ip EH, Marsh AP et al. Measuring disability in older adults: The International Classification System of Functioning, Disability and Health (ICF) framework. Geriatr Gerontol Int 2008;8:48-54.

30. Groessl EJ, Kaplan RM, Rejeski WJ et al. Health-related quality of life in older adults at risk for disability. Am J Prev Med 2007;33:214.

31. Alberti K, Eckel RH, Grundy SM et al. Harmonizing the metabolic syndrome: A joint interim statement of the International Diabetes Federation Task Force on Epidemiology and Prevention; National Heart, Lung, and Blood Institute; American Heart Association; World Heart Federation; International Atherosclerosis Society; and International Association for the Study of Obesity. Circulation 2009;120:1640-1645.

32. Aboyans V, Criqui MH, Abraham P et al. Measurement and interpretation of the ankle-brachial index. A scientific statement from the American Heart Association. Circulation 2012;126:2890-2909.

33. Teng E, Chui H. The Modified Mini-Mental State (3MS) Examination. J Clin Psychiatry 1987;48:314-318.

34. Carriere I, Peres K, Ancelin ML et al. Metabolic syndrome and disability: Findings from the Prospective Three-City Study. J Gerontol A Biol Sci Med Sci 2014;69A:79-86.

35. Okoro C, Zhong Y, Ford E et al. Association between the metabolic syndrome and its components and gait speed among US adults aged 50 years and older: A cross-sectional analysis. BMC Public Health 2006;6:282-290.

36. Kuo CK, Lin LY, Yu YH et al. Inverse association between insulin resistance and gait speed in non diabetic older men: Results from the US National Health and Nutrition Examination Survey (NHANES) 1999 2002. BMC Geriatr 2009;9:49-55.

37. Landi F, Russo A, Cesari M et al. HDL-cholesterol and physical performance: Results from the Ageing and Longevity Study in the Sirente geographic area (ilSIRENTE study). Age Ageing 2007;36:514-520.

38. Sumner AD, Sardi GL, Reed JF. Components of the metabolic syndrome differ between young and old adults in the US population. J Clin Hypertens (Greenwich) 2012;14:502-506.

39. Goodpaster BH, Krishnaswami S, Harris TB et al. Obesity, regional body fat distribution, and the metabolic syndrome in older men and women. Arch Intern Med 2005;165:777-783.

40. Ervin RB. Prevalence of metabolic syndrome among adults 20 years of age and over, by sex, age, race and ethnicity, and body mass index: United States. Natl Health Stat Report 2009;13:1-8.

41. Silventoinen K, Pankow J, Jousilahti P et al. Educational inequalities in the metabolic syndrome and coronary heart disease among middle-aged men and women. Int J Epidemiol 2005;34:327-334.
42. Loucks EB, Rehkopf DH, Thurston RC et al. Socioeconomic disparities in metabolic syndrome differ by gender: Evidence from NHANES III. Ann Epidemiol 2007;17:19-26.

43. Bouchard DR, Langlois M, Brochu M et al. Metabolically healthy obese women and functional capacity. Metab Syndr Relat Disord 2011;9: $225-229$.

44. Laudisio A, Bandinelli S, Gemma A et al. Metabolic syndrome and functional ability in older age: The InCHIANTI study. Clin Nutr 2014;33:626-633.

45. Roriz-Cruz M, Rosset I, Wada T et al. Stroke-Independent association between metabolic syndrome and functional dependence, depression, and low quality of life in elderly community-dwelling Brazilian people. J Am Geriatr Soc 2007;55:374-382.

46. Tsai A, Tsai H. Functional impairment but not metabolic syndrome is associated with depression in older Taiwanese: Results from the Social Environment and Biomarkers of Aging Study. J Nutr Health Aging 2012;16:492-496.

47. Jaeschke R, Singer J, Guyatt GH. Measurement of health status: Ascertaining the minimal clinically important difference. Control Clin Trials 1989; 10:407-415.

\section{APPENDIX 1: RESEARCH INVESTIGATORS FOR THE LIFE STUDY}

The Lifestyle Interventions and Independence for Elders Study is funded by National Institutes of Health/National Institute on Aging Cooperative Agreement U01AG22376 and Supplement U01AG022376-05A2S from the National Heart, Lung, and Blood Institute, and sponsored in part by the Intramural Research Program, National Institute on Aging, NIH.

The research is partially supported by the Claude D. Pepper Older Americans Independence Centers at the University of Florida (1P30AG028740), Tufts University (1P30AG031679), University of Pittsburgh (P30A G024827), and Yale University (P30AG021342), and the NIH/NCRR CTSA at Stanford University (UL1RR025744).

LIFE investigators are also partially supported by the following:

Dr. Thomas Gill (Yale University) is the recipient of an Academic Leadership Award (K07AG3587) from the National Institute on Aging.

Dr. Carlos Fragoso (Spirometry Reading Center, Yale University) is the recipient of a Career Development Award from the Department of Veterans Affairs.

Dr. Roger Fielding (Tufts University) is partially supported by the U.S. Department of Agriculture under agreement 58-1950-7-707. Any opinions, findings, conclusion, or recommendations expressed in this publication are those of the author(s) and do not necessarily reflect the view of the U.S. Department of Agriculture.

\section{Administrative Coordinating Center, University of Florida, Gainesville, FL}

Marco Pahor, MD-Principal Investigator of the LIFE Study

Jack M. Guralnik, MD, PhD-Co-Investigator of the LIFE Study (University of Maryland School of Medicine, Baltimore, MD)

Christiaan Leeuwenburgh, $\mathrm{PhD}$

Connie Caudle

Lauren Crump, MPH

Latonia Holmes

Jocelyn Lee, $\mathrm{PhD}$

Ching-ju Lu, MPH 
Data Management, Analysis and Quality Control Center, Wake Forest University, Winston Salem, NC

Michael E. Miller, PhD-DMAQC Principal Investigator Mark A. Espeland, PhD-DMAQC Co-Investigator

Walter T. Ambrosius, PhD

William Applegate, MD

Daniel P. Beavers, PhD, MS

Robert P. Byington, PhD, MPH, FAHA

Delilah Cook, CCRP

Curt D. Furberg, MD, PhD

Lea N. Harvin, BS

Leora Henkin, MPH, Med

John Hepler, MA

Fang-Chi Hsu, PhD

Laura Lovato, MS

Wesley Roberson, BSBA

Julia Rushing, BSPH, MStat

Scott Rushing, BS

Cynthia L. Stowe, MPM

Michael P. Walkup, MS

Don Hire, BS

W. Jack Rejeski, PhD

Jeffrey A. Katula, PhD, MA

Pete H. Brubaker, PhD

Shannon L. Mihalko, PhD

Janine M. Jennings, PhD

\section{National Institutes of Health, Bethesda, MD}

Evan C. Hadley, MD (National Institute on Aging)

Sergei Romashkan, MD, PhD (National Institute on Aging)

Denise E. Bonds, MD, MPH (National Heart, Lung, and Blood Institute)

Kushang V. Patel, PhD (National Institute on Aging)

\section{Field Centers}

Northwestern University, Chicago, IL

Mary M. McDermott, MD-Field Center Principal Investigator

Bonnie Spring, $\mathrm{PhD}$-Field Center Co-Investigator

Joshua Hauser, MD-Field Center Co-Investigator

Diana Kerwin, MD-Field Center Co-Investigator

Kathryn Domanchuk, BS

Rex Graff, MS

Alvito Rego, MA

\section{Pennington Biomedical Research Center, Baton Rouge, LA}

Timothy S. Church, MD, PhD, MPH—Field Center Principal Investigator

Steven N. Blair, PED (University of South Carolina)

Valerie H. Myers, PhD

Ron Monce, PA-C

Nathan E. Britt, NP

Melissa Nauta Harris, BS

Ami Parks McGucken, MPA, BS

Ruben Rodarte, MBA, MS, BS

Heidi K. Millet, MPA, BS
Catrine Tudor-Locke, PhD, FACSM

Ben P. Butitta, BS

Sheletta G. Donatto, MS, RD, LDN, CDE

Shannon H. Cocreham, BS

\section{Stanford University, Palo Alto, CA}

Abby C. King, PhD-Field Center Principal Investigator Cynthia M. Castro, PhD

William L. Haskell, PhD

Randall S. Stafford, MD, PhD

Leslie A. Pruitt, $\mathrm{PhD}$

Kathy Berra, MSN, NP-C, FAAN

Veronica Yank, MD

\section{Tufts University, Boston, MA}

Roger A. Fielding, PhD-Field Center Principal Investigator Miriam E. Nelson, PhD-Field Center Co-Investigator

Sara C. Folta, PhD-Field Center Co-Investigator

Edward M. Phillips, MD

Christine K. Liu, MD

Erica C. McDavitt, MS

Kieran F. Reid, MSc, MPH

Won S. Kim, BS

Vince E. Beard, BS

University of Florida, Gainesville, FL

Todd M. Manini, PhD-Field Center Principal Investigator Marco Pahor, MD-Field Center Co-Investigator

Stephen D. Anton, PhD

Susan Nayfield, MD

Thomas W. Buford, PhD

Michael Marsiske, PhD

Bhanuprasad D. Sandesara, MD

Jeffrey D. Knaggs, BS

Megan S. Lorow, BS

William C. Marena, MT, CCRC

Irina Korytov, MD

Holly L. Morris, MSN, RN, CCRC (Brooks Rehabilitation Clinical Research Center, Jacksonville, FL)

Margo Fitch, PT (Brooks Rehabilitation Clinical Research Center, Jacksonville, FL)

Floris F. Singletary, MS, CCC-SLP (Brooks Rehabilitation Clinical Research Center, Jacksonville, FL)

Jackie Causer, BSH, RN (Brooks Rehabilitation Clinical Research Center, Jacksonville, FL)

Katie A. Radcliff, MA (Brooks Rehabilitation Clinical Research Center, Jacksonville, FL)

\section{University of Pittsburgh, Pittsburgh, PA}

Anne B. Newman, MD, MPH-Field Center Principal Investigator

Stephanie A. Studenski, MD, MPH-Field Center Co-Investigator

Bret H. Goodpaster, PhD

Nancy W. Glynn, PhD

Oscar Lopez, MD

Neelesh K. Nadkarni, MD, PhD

Kathy Williams, RN, BSEd, MHSA 
Mark A. Newman, PhD

George Grove, MS

Janet T. Bonk, MPH, RN

Jennifer Rush, MPH

Piera Kost, BA (deceased)

Diane G. Ives, MPH

\section{Wake Forest University, Winston Salem, NC}

Stephen B. Kritchevsky, PhD-Field Center Principal Investigator

Anthony P. Marsh, PhD-Field Center Co-Investigator

Tina E. Brinkley, $\mathrm{PhD}$

Jamehl S. Demons, MD

Kaycee M. Sink, MD, MAS

Kimberly Kennedy, BA, CCRC

Rachel Shertzer-Skinner, MA, CCRC

Abbie Wrights, MS

Rose Fries, RN, CCRC

Deborah Barr, MA, RHEd, CHES

\section{Yale University, New Haven, CT}

Thomas M. Gill, MD-Field Center Principal Investigator Robert S. Axtell, PhD, FACSM-Field Center Co-Investigator (Southern Connecticut State University, Exercise Science Department)

Susan S. Kashaf, MD, MPH (VA Connecticut Healthcare System)

Nathalie de Rekeneire, MD, MS

Joanne M. McGloin, MDiv, MS, MBA

Karen C. Wu, RN

Denise M. Shepard, RN, MBA

Barbara Fennelly, MA, RN

Lynne P. Iannone, MS, CCRP

Raeleen Mautner, PhD

Theresa Sweeney Barnett, MS, APRN

Sean N. Halpin, MA

Matthew J. Brennan, MA

Julie A. Bugaj, MS

Maria A. Zenoni, MS

Bridget M. Mignosa, MS

\section{Cognition Coordinating Center, Wake Forest University, Winston Salem, NC}

Jeff Williamson, MD, MHS-Center Principal Investigator Kaycee M. Sink, MD, MAS-Center Co-Investigator Hugh C. Hendrie, MB, ChB, DSc (Indiana University) Stephen R. Rapp, PhD

Joe Verghese, MB, BS (Albert Einstein College of Medicine of Yeshiva University)

Nancy Woolard

Mark Espeland, $\mathrm{PhD}$

Janine Jennings, $\mathrm{PhD}$

\section{Electrocardiogram Reading Center, University of} Florida, Gainesville, FL

Carl J. Pepine, MD, MACC

Mario Ariet, $\mathrm{PhD}$

Eileen Handberg, PhD, ARNP

Daniel Deluca, BS

James Hill, MD, MS, FACC

Anita Szady, MD

Spirometry Reading Center, Yale University, New Haven, CT

Geoffrey L. Chupp, MD

Gail M. Flynn, RCP, RFT

Thomas M. Gill, MD

(Hankinson Consulting, Inc.)

John L. Hankinson, PhD

Carlos A. Vaz Fragoso, MD

\section{Cost Effectiveness Analysis Center}

Erik J. Groessl, PhD (University of California, San Diego and VA San Diego Healthcare System)

Robert M. Kaplan, PhD (Office of Behavioral and

Social Sciences Research, National Institutes

of Health) 